\title{
Reproducibility of the airway response to an exercise protocol standardized for intensity, duration, and inspired air conditions, in subjects with symptoms suggestive of asthma
}

\author{
Sandra D Anderson ${ }^{1,2^{*}}$, David S Pearlman ${ }^{3}$, Kenneth W Rundell ${ }^{4}$, Claire P Perry ${ }^{5}$, Homer Boushey ${ }^{6}$, \\ Christine A Sorkness ${ }^{7}$, Sara Nichols ${ }^{8}$, John M Weiler ${ }^{8,9}$
}

\begin{abstract}
Background: Exercise testing to aid diagnosis of exercise-induced bronchoconstriction (EIB) is commonly performed. Reproducibility of the airway response to a standardized exercise protocol has not been reported in subjects being evaluated with mild symptoms suggestive of asthma but without a definite diagnosis. This study examined reproducibility of $\%$ fall in $\mathrm{FEV}_{1}$ and area under the $\mathrm{FEV}_{1}$ time curve for 30 minutes in response to two exercise tests performed with the same intensity and duration of exercise, and inspired air conditions.
\end{abstract}

Methods: Subjects with mild symptoms of asthma exercised twice within approximately 4 days by running for 8 minutes on a motorized treadmill breathing dry air at an intensity to induce a heart rate between $80-90 \%$ predicted maximum; reproducibility of the airway response was expressed as the $95 \%$ probability interval.

Results: Of 373 subjects challenged twice 161 were positive ( $\geq 10 \%$ fall $\mathrm{FEV}_{1}$ on at least one challenge). The EIB was mild and $77 \%$ of subjects had $<15 \%$ fall on both challenges. Agreement between results was $76.1 \%$ with $56.8 \%$ (212) negative $\left(<10 \%\right.$ fall $\left.\mathrm{FEV}_{1}\right)$ and $19.3 \%$ (72) positive on both challenges. The remaining $23.9 \%$ of subjects had only one positive test. The $95 \%$ probability interval for reproducibility of the $\%$ fall in $\mathrm{FEV}_{1}$ and $\mathrm{AUC}_{0-30}$ min was $\pm 9.7 \%$ and \pm $251 \%$ for all 278 adults and $\pm 13.4 \%$ and $\pm 279 \%$ for all 95 children. The $95 \%$ probability interval for reproducibility of $\%$ fall in $\mathrm{FEV}_{1}$ and $\mathrm{AUC}_{0-30}$ min for the 72 subjects with two tests $\geq 10 \%$ fall $\mathrm{FEV}_{1}$ was $\pm 14.6 \%$ and $\pm 373 \%$ and for the 34 subjects with two tests $\geq 15 \%$ fall FEV 1 it was $\pm 12.2 \%$ and $\pm 411 \%$. Heart rate and estimated ventilation achieved were not significantly different either on the two test days or when one test result was positive and one was negative.

Conclusions: Under standardized, well controlled conditions for exercise challenge, the majority of subjects with mild symptoms of asthma demonstrated agreement in test results. Performing two tests may need to be considered when using exercise to exclude or diagnose EIB, when prescribing prophylactic treatment to prevent EIB and when designing protocols for clinical trials.

\section{Background}

Exercise is a widely recognised stimulus for provoking transient airway narrowing. Exercise-induced bronchoconstriction (EIB) is the term used to describe this phenomenon. The most commonly used measure to express severity of EIB is the post-exercise fall in forced

\footnotetext{
* Correspondence: sandy@med.usyd.edu.au

'Department of Respiratory \& Sleep Medicine, 11 West, Royal Prince Alfred

Hospital, Missenden Road, Camperdown NSW 2050, Australia

Full list of author information is available at the end of the article
}

expiratory volume in one second $\left(\mathrm{FEV}_{1}\right)$, as a percentage of the pre-exercise value [1]. $\mathrm{A} \geq 10 \%$ fall in $\mathrm{FEV}_{1}$ is reported to provide the best discrimination between asthmatic and normal responses in laboratory based running tests [2]. It is also the value suggested as the cut off for a positive test in the ATS and ERS guidelines for testing for EIB $[3,4]$. A second index of EIB severity is the area under the \% fall in $\mathrm{FEV}_{1}$ time curve $\left(\mathrm{AUC}_{0-30}\right.$ min $)$, which summarizes the extent and duration of bronchoconstriction. This second index is used to assess the benefit of 
medications that enhance recovery to a greater extent than their benefit on the immediate post exercise fall in $\mathrm{FEV}_{1}$ [5]. The $\mathrm{AUC}_{0-30}$ min reflects the contribution of the numerous mediators involved in EIB [6,7].

EIB commonly occurs in people with clinically recognized asthma [8] and has been reported in school children, elite athletes, and military recruits without other clinical signs and symptoms of asthma [9-11]. EIB is often the first indication of asthma [12] so it is important to diagnose and then treat underlying asthma recognized by exercise intolerance. We recently studied and reported a large number of adults and children with signs and symptoms suggestive of asthma but without a definitive diagnosis [13]. The study investigated sensitivity and specificity of airway responsiveness to methacholine and mannitol to identify EIB and a physician diagnosis of asthma [13]. The study examined duplicate controlled exercise challenges in 373 subjects and the data provided an opportunity to examine reproducibility of the airway response to exercise in the type of individual most likely to be referred for exercise testing for EIB.

Exercise testing to identify EIB in the laboratory is affected by the type of exercise, intensity and duration of exercise, inspired air conditions, baseline lung function and time since last medication or exercise. This paper reports the reproducibility of the $\%$ fall in $\mathrm{FEV}_{1}$ and $\mathrm{AUC}_{0-30} \mathrm{~min}$ in response to an exercise protocol that carefully controlled these variables.

\section{Methods}

\section{Subjects: Inclusion/Exclusion Criteria}

Subjects were enrolled if they were aged 6-50 years with a BMI of $<35$, and reported signs and symptoms suggestive of asthma according to the National Institute of Health (NIH) Questionnaire [14]. They were required to have an $\mathrm{FEV}_{1} \geq 70 \%$ of the predicted value at the Screening Visit $[15,16]$. Subjects were required to have a National Asthma Education and Prevention Program (NAEPPII) asthma severity score of Step 1 with neither a firm diagnosis of asthma nor an exclusion of the diagnosis of asthma. Step 1 of NAEPPII is the mildest and is defined as symptoms $\leq 2$ times per week, asymptomatic and normal peak expiratory flow measurements between exacerbations, exacerbations from only a few hours to a few days, night time symptom frequency of $\leq 2$ times per month, $\mathrm{FEV}_{1}$ or $\mathrm{PEF} \geq 80 \%$ predicted and $\mathrm{PEF}$ variability $\leq 20 \%$.

Subjects were excluded from participation if they: had any known other pulmonary disease; had smoked more than 1 cigarette per week within the past year or had a $\geq 10$ pack year smoking history; had a respiratory tract infection within the previous 4 weeks; had been skin test positive to aeroallergens that were present in the environment during the time of enrolment and reported worsening of symptoms when exposed to these aeroallergens during the study; had been diagnosed at the Screening Visit as definitively (95 to 100\% likelihood) having or not having asthma; had clinically significantly abnormal chest $\mathrm{x}$-ray or ECG; or had failed to observe washout time of medications that would interfere with exercise (including, but not limited to, no use of corticosteroids within 4 weeks of the Screening Visit).

The disposition of the study population is given in Figure 1. The data presented are from the 375 subjects in the per protocol population that included all subjects with no major protocol violations previously reported [13]. Of the 375 subjects, two completed only one exercise challenge leaving 373 who completed two exercise tests; there were 95 children and 278 adults.

\section{Procedures}

The protocol was approved by institutional review boards and performed at 25 sites in the USA. Each subject or parent gave written informed consent or assent for minors $<18$ years of age. At screening the following were assessed: eligibility; demography; medical history; medications; spirometry with reversibility (following $360 \mathrm{mcg}$ of albuterol/salbutamol from a pressurised metered dose inhaler); and allergy skin-prick testing to 10 common allergens (positive test taken as a wheal size $\geq 3 \mathrm{~mm}$ of the control). The NIH NAEPPII Questionnaire was administered and a score was assigned.

Exercise was performed on two separate occasions beginning 1 - 4 days after the screening visits and within $2 \mathrm{hrs}$ of the same time of day. Medication withholding was confirmed (Table 1), and spirometry was measured to determine consistency with values obtained at screening as previously described [13]. The exercise was performed on consecutive visits ( 2 and 3 ) with the second challenge being in 1 - 4 days after the first. $\mathrm{FEV}_{1}$ needed to be $>70 \%$ predicted and within $15 \%$ of $\mathrm{FEV}_{1}$ at screening in order for an exercise challenge to be performed.

\section{Exercise protocol}

Exercise was performed by running on a motorized treadmill while breathing medical grade dry air $\left(20-25^{\circ} \mathrm{C}\right)$ from a reservoir (Douglas Bag) via a two-way non-rebreathing valve [17]. Subjects began by walking then running with the treadmill speed at $2.5 \mathrm{mph}$ with $2.5 \%$ incline. Speed and incline were increased over 2 minutes so that heart rate (HR) reached $80-90 \%$ of predicted maximum (220age) and then was maintained for 6 minutes for a total duration of 8 minutes. This intensity aimed to achieve a ventilation rate between 14 and 21 times FEV1 L values that represent between 40 and $60 \%$ of maximum predicted ventilation $\left(35 \times \mathrm{FEV}_{1}\right)$ [18]. The challenge could be stopped at any time. HR was monitored during and for 30 min after exercise. 


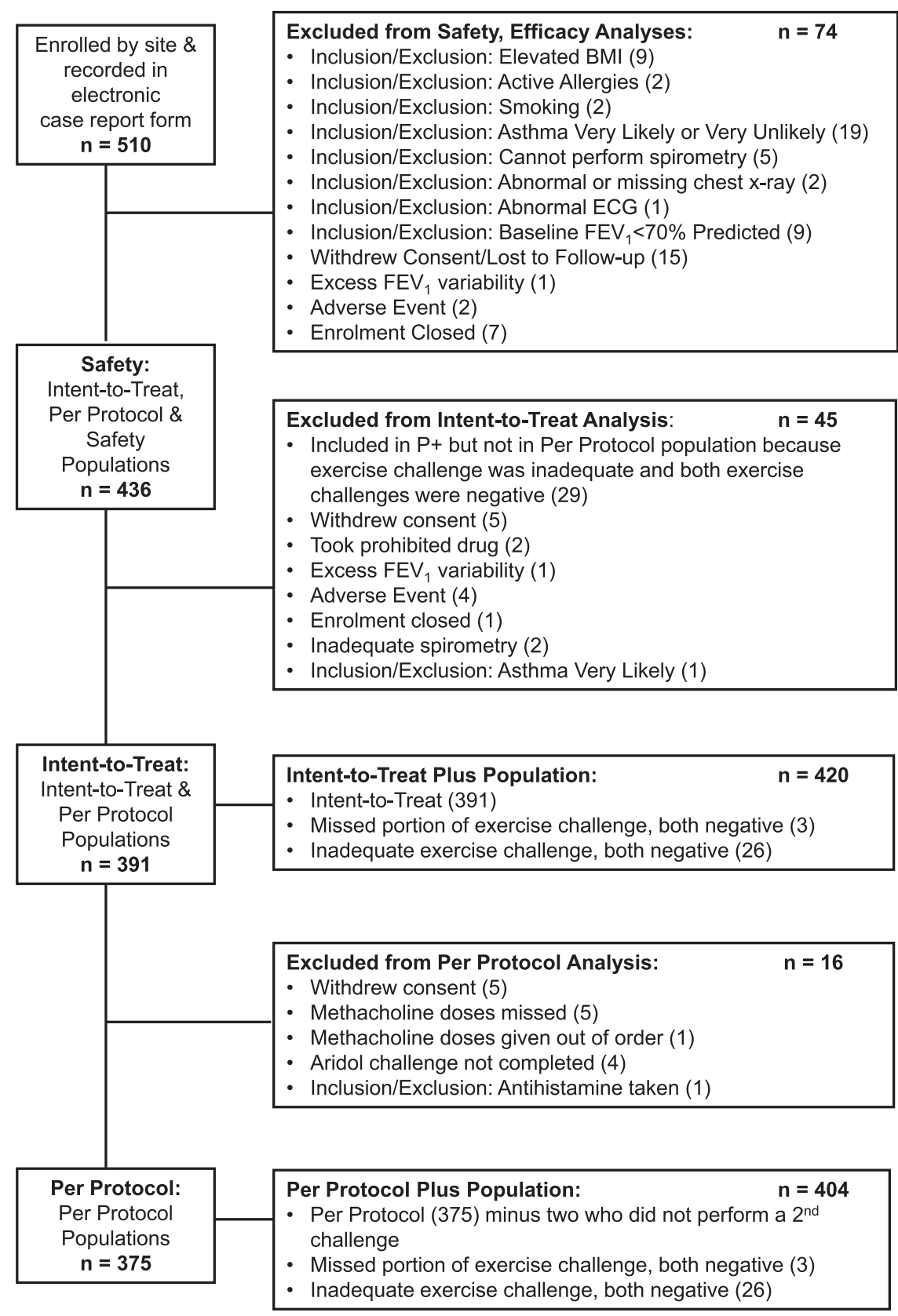

Figure 1 Subject Disposition. Reproduced from Respiratory Research 2009, 10:4 (23 January 2009) with the permission of the authors.

$\mathrm{FEV}_{1}$ and $\mathrm{FVC}$ were measured before and $\mathrm{FEV}_{1}$ (not FVC) was measured 5, 10, 15, and 30 minutes after exercise. The \% fall in $\mathrm{FEV}_{1}$ was calculated by subtracting the lowest value recorded after exercise taking the best of two acceptable attempts at each time point, from the value measured immediately before exercise, expressed as a percentage of the pre-exercise value. Values were not rounded; a $9.99 \%$ fall was considered negative. A subject was deemed positive if there was a fall of $\geq 10 \%$ in $\mathrm{FEV}_{1}$ at one time point on at least one of the two exercise challenges [3,4]. Values are reported as mean and standard deviation (SD). Values for $\mathrm{FEV}_{1}$ post-exercise that remained higher than the pre-exercise value were censored as $0 \%$ falls. The $\mathrm{AUC}_{0-30}$ min was calculated by the trapezoidal method [19] and expressed as \% fall in $\mathrm{FEV}_{1} \mathrm{~min}^{-1}$.

Spirometry data were captured by using ClinDataLink ${ }^{\odot}$ (CDL) (CompleWare Corporation, North Liberty, IA) and met or exceeded the requirements proposed by American Thoracic Society/European Respiratory 
Table 1 Required medication withholding periods for medications before exercise tests

\begin{tabular}{|c|c|c|}
\hline & Factor & $\begin{array}{l}\text { Withholding } \\
\text { Period }\end{array}$ \\
\hline \multirow[t]{4}{*}{ Inhaled agents } & $\begin{array}{l}\text { Short acting bronchodilators (isoproterenol, isoetharine, metaproterenol, albuterol, levalbuterol, terbutaline) } \\
\text { (e.g. Proventil }{ }^{\oplus} \text { or Ventolin }{ }^{\oplus} \text { ) }\end{array}$ & $8 \mathrm{hr}$ \\
\hline & Inhaled anticholinergics or combination products (e.g. Atrovent ${ }^{\oplus}$ or Combivent ${ }^{\oplus}$ ) & 1 week \\
\hline & Long acting inhaled bronchodilators (salmeterol, formoterol) (e.g. Serevent ${ }^{\oplus}$ or Foradil ${ }^{\oplus}$ ) & 2 weeks \\
\hline & Inhaled corticosteroid/long acting inhaled bronchodilator combination (e.g. Advair( ) & 4 weeks \\
\hline \multirow{5}{*}{$\begin{array}{l}\text { Oral } \\
\text { bronchodilators }\end{array}$} & Theophylline & $24 \mathrm{hr}$ \\
\hline & Intermediate theophylline & $48 \mathrm{hr}$ \\
\hline & Long acting theophylline & $48 \mathrm{hr}$ \\
\hline & Standard $\beta$-agonist tablets & $24 \mathrm{hr}$ \\
\hline & Long acting $\beta$-agonist tablets & $48 \mathrm{hr}$ \\
\hline Corticosteroids & There is no washout for topical corticosteroids applied to skin unless they are high potency steroids & 4 weeks \\
\hline \multirow{7}{*}{$\begin{array}{l}\text { Other } \\
\text { medications }\end{array}$} & Hydroxyzine, cetirizine (and other antihistamines) & $72 \mathrm{hr}$ \\
\hline & Tiotropium bromide & $72 \mathrm{hr}$ \\
\hline & Nasals corticosteroids & 1 week \\
\hline & $\beta$-blockers & 1 week \\
\hline & Cromolyn sodium & 2 weeks \\
\hline & Nedocromil & 2 weeks \\
\hline & Leukotriene modifiers & 6 weeks \\
\hline Foods & Coffee, tea, cola drinks, chocolate (caffeinated foods) & $12 \mathrm{hr}$ \\
\hline \multicolumn{2}{|c|}{ Strenuous exercise or exposure to cold air to a level that would be expected to interfere with challenges } & $12 \mathrm{hr}$ \\
\hline \multicolumn{2}{|l|}{ Tobacco } & $6 \mathrm{hr}$ \\
\hline
\end{tabular}

Society Joint Statement [20]. Calibration was verified each day at three flow rates before use. $\mathrm{WebCDL}^{\circledR}$ software displayed an electronic record of the volume-time curves, flow-volume displays, and flow-time displays.

An estimate was made of ventilation in the $2^{\text {nd }}$ and $6^{\text {th }}$ minutes of exercise based on the relationship between speed and incline of treadmill and oxygen consumption in $\mathrm{ml}$ [21]. The ventilatory equivalent was estimated as $27 \mathrm{~L}$ per $\mathrm{L}$ of $\mathrm{VO}_{2}$ [22], and ventilation was expressed as \% of maximum voluntary ventilation (MVV). The estimate of oxygen consumption in mls was:

1.262 *weight* $\left(3.5+\left(5.36^{*}\right.\right.$ speed $)+\left(0.24^{*}\right.$ speed $^{*}$ incline)) for running

$1.262^{*}$ weight" $\left(3.5+\left(2.68^{*}\right.\right.$ speed $)+\left(0.48^{*}\right.$ speed*incline)) for walking.

Weight is expressed in kilograms and speed is expressed in miles per hour. Three miles per hour was taken to be running.

\section{Statistical Analysis}

Reproducibility of the exercise test response was illustrated using a Bland-Altman-type plot [23] and calculated using the method of Chinn [24]. In brief, the standard deviation of a single measurement was calculated by dividing the standard deviation of the differences in \% fall in $\mathrm{FEV}_{1}$ values between the two tests (i.e. 7.6 for the whole group) by the square root of 2 giving a $5.4 \%$ fall, from which we calculated a $95 \%$ probability interval of $\pm 10.8 \%$. This interval defines a $95 \%$ probability that the difference between any single measurement and the true value for the subject is within that range. This gives information about variability of the response that can be expected in an individual with repeated testing.

\section{Results}

\section{Demography}

For the per protocol population $(\mathrm{n}=375)$ : females comprised 51.5\%; subjects were 76.3\% Caucasian, 8.3\% Hispanic and 8.5\% Black; subjects had near-normal baseline spirometry (Table 2 ); and $7.2 \%$ responded positively to a bronchodilator with $\geq 12 \%$ and $\geq 200 \mathrm{ml}$ increase in $\mathrm{FEV}_{1}$ above baseline. The characteristics of the 95 children and 278 adults are summarised in Table 2. The mean NAEPPII asthma score was 1.22 (SD 0.52) for the adults and $1.21(0.48)$ for the children. Positive skin tests to at least one allergen were seen in $78 \%$ of the adults and children.

\section{Reproducibility of the Response}

The 373 subjects who completed two exercise challenges did so within $2.6 \pm 3.2$ (median 2 ) days. The agreement 
Table 2 Anthropometric data, forced expiratory volume in one second, and smoking history in the per protocol population

\begin{tabular}{|c|c|c|c|c|c|c|c|c|}
\hline Children & & & & & & & & \\
\hline $\mathrm{N}=95$ & Age (yr) & BMI & $\mathrm{FEV}_{1}$ (L) & $\%$ Pred FEV 1 & $\%$ Rise Post BD FEV ${ }_{1}$ (L) & $\begin{array}{c}\text { Pack Yrs } \\
N=1\end{array}$ & $\mathrm{Ht}(\mathrm{cm})$ & Wt (kg) \\
\hline Mean & 13.0 & 21.5 & 2.83 & 94.2 & 6.9 & 0.43 & 157.6 & 54.9 \\
\hline SD & 3.0 & 4.3 & 0.92 & 12.5 & 12.8 & & 16.7 & 18.2 \\
\hline Range & $6-17$ & 13.4-33.1 & $1.15-5.15$ & $63.7-127.4$ & $0-115$ & & 118-192 & $20-102$ \\
\hline Median & 14 & 21.3 & 2.69 & 92.2 & 4.4 & & 158 & 54.9 \\
\hline \multicolumn{9}{|l|}{ Adults } \\
\hline$N=278$ & Age (yr) & BMI & $\mathrm{FEV}_{1}(\mathrm{~L})$ & $\%$ Pred FEV 1 & $\%$ Rise Post BD FEV ${ }_{1}$ (L) & $\begin{array}{c}\text { Pack Yrs } \\
\mathrm{N}=44\end{array}$ & $\mathrm{Ht}(\mathrm{cm})$ & Wt (kg) \\
\hline Mean & 28.2 & 25.3 & 3.49 & 93.4 & 5.1 & 3 & 170.7 & 74.2 \\
\hline SD & 8.8 & 4.1 & 0.71 & 10.2 & 5.8 & 2.9 & 9.7 & 15.7 \\
\hline Range & $18-50$ & $14.7-34.9$ & $1.97-5.62$ & $70.3-140.1$ & $0-51.5$ & $0-9$ & $150-204$ & $38-135$ \\
\hline Median & 25 & 25.0 & 3.38 & 93.3 & 3.99 & 2.5 & 170 & 72.3 \\
\hline
\end{tabular}

for exercise response was $76.1 \%$ with $56.8 \%$ (212) negative and $19.3 \%$ (72) positive on both challenges. Seventy-two, 34, and 19 of the 373 subjects had FEV falls of $\geq 10 \%, \geq 15 \% \geq 20 \%$, respectively on both exercise challenges.

The reproducibility (95\% probability value) of the $\%$ fall in $\mathrm{FEV}_{1}$ and the AUC \% fall in $\mathrm{FEV}_{1} \mathrm{~min}^{-1}$ for the whole group and for adults and children separately are given in Table 3, together with mean and highest falls in FEV . The variation for the response in all the adults and all the children is illustrated in Figures 2 and in Figures $3 a$ and $3 \mathrm{~b}$ for those with $\geq 10 \%$ fall in $\mathrm{FEV}_{1}$ on both tests.

The reproducibility of the exercise response in relation to the different NAEPPII scores is given in Table 3. There was no relationship between the NAEPII score and the severity of the response to exercise expressed as the $\%$ fall in $\mathrm{FEV}_{1}$ after exercise (Figure 4).

\section{Exercise Response}

Post-exercise, 163 of the 375 subjects had $\geq 10 \%$ fall in $\mathrm{FEV}_{1}$ (mean \% fall \pm SD was $19.1 \% \pm 9.25$ or $610 \pm$ $330 \mathrm{ml}$ ) after at least one exercise challenge with 86 having $\geq 15 \%$ and $56 \geq 20 \%$ fall in $\mathrm{FEV}_{1}$. Those 77 with very mild EIB i.e. 10 to $15 \%$ fall in $\mathrm{FEV}_{1}$ had a mean fall of $12.3 \% \pm 1.5$ or $395 \pm 116 \mathrm{ml}$. The distribution of the values for the maximum \% fall in $\mathrm{FEV}_{1}$ is given in Figure 5 . Of the 163 subjects, 161 completed two exercise challenges with 88 having a fall in $\mathrm{FEV}_{1}$ of $\geq 10 \%$ at two or more time points after exercise and 157 having a fall in $\mathrm{FEV}_{1} \geq 200 \mathrm{ml}$ (median $530 \mathrm{ml}$ ). On the first exercise challenge 119 had $\geq 10 \%$ fall in $\mathrm{FEV}_{1} ; 67$ had $\geq 15 \%$ fall in $\mathrm{FEV}_{1}$. Of those 27 with a $\geq 12 \%$ and $200 \mathrm{ml}$ after bronchodilator, 10 were positive to and 7 were negative to both exercise challenges, and 10 were positive to only one challenge.
There were 89 subjects who had a positive test on only one of two challenges; 45 on the first challenge and 44 on the $2^{\text {nd }}$ challenge (Figure 6a). For the 89 the mean difference in $\mathrm{FEV}_{1}$ between the positive and negative test result was $308 \pm 173 \mathrm{ml}$. For the 44 of 161 subjects identified as positive with a fall in $\mathrm{FEV}_{1} \geq 10 \%$, only on the second challenge, 39 (89\%) had a fall in $\mathrm{FEV}_{1}$ $\leq 16 \%$ and only three subjects had a fall in $\mathrm{FEV}_{1}>20 \%$. Fifty-five of the 373 subjects had only a rise in $\mathrm{FEV}_{1}$ from baseline on the $1^{\text {st }}$ challenge; only 7 of these 55 subjects had $\geq 10 \%$ fall in $\mathrm{FEV}_{1}$ on the $2^{\text {nd }}$ challenge.

The mean values for $\%$ fall in $\mathrm{FEV}_{1}$ for adults and children and for those with two negative $(<10 \%$ fall), two positive $(\geq 10 \%$ fall) and one positive and one negative test on each occasion are illustrated Figure 6 a. $\mathrm{AUC}_{0-30}$ min associated with these \% falls in $\mathrm{FEV}_{1}$ is given in Figure $6 \mathrm{~b}$. There was no significant difference in the response to exercise between adults and children. There was a significant correlation between the maximum \% fall in $\mathrm{FEV}_{1}$ and the corresponding 'maximum' $\mathrm{AUC}_{0-30 \text { min }}(\mathrm{r}=0.87, \mathrm{p}<0.001)$.

\section{Work Load}

The exercise load was similar on both tests days. Exercise resulted in a $\mathrm{HR}, \%$ predicted maximum at 2 and 6 minutes of $82.1 \% \pm 5.6$ and $86.6 \% \pm 8.9$ on Day 1 and of $81.5 \% \pm 6.7$ and $89.9 \% \pm 6.5$ on Day 2 in adults $(\mathrm{p}=\mathrm{NS})$ and $81.9 \% \pm 5.7$ and $85.9 \% \pm 10.3$ on Day 1 and $81.8 \% \pm 6.3$ and $86.7 \% \pm 4.9$ on Day 2 in children $(\mathrm{p}=\mathrm{NS})$. There was no significant difference in the estimated ventilation expressed as a \% of maximum voluntary ventilation between Days 1 and 2 for either the adults (Day 1 at 2 min 56.8\% \pm 15.3 and Day $258.0 \% \pm$ 15.2) and children (Day 1 at $2 \mathrm{~min} 54.7 \% \pm 13.1$ and Day $256.3 \% \pm 11.9)$. 


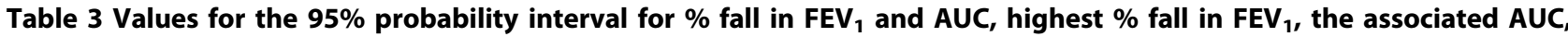
mean $\%$ fall FEV F $_{1}$ and the SD of the difference between two tests shown for Groups and for different NAEPP values

\begin{tabular}{|c|c|c|c|c|c|c|}
\hline & $\begin{array}{l}\% \text { Fall } \\
\text { FEV }_{1}\end{array}$ & AUC $\%$ fall $\mathrm{FEV}_{1}$ min $^{-}$ & $\begin{array}{c}\text { mean } \pm \text { SD } \\
\text { Highest } \\
\% \text { Fall FEV }_{1}\end{array}$ & $\begin{array}{c}\text { mean } \pm \text { SD AUC } \% \text { fall FEV } \\
\text { min }^{-1}\end{array}$ & $\begin{array}{c}\text { Mean } \\
\% \text { fall } F E V_{1} \text { two } \\
\text { tests }\end{array}$ & $\begin{array}{c}\text { SD } \\
\text { difference } \\
\text { two tests } \\
\% \text { fall } \mathrm{FEV}_{1}\end{array}$ \\
\hline $\begin{array}{c}\text { Whole } \\
\text { Group } \\
\mathrm{n}=373\end{array}$ & $\pm 10.8 \%$ & $\pm 259 \%$ & $10.95 \% \pm 9.4$ & $-221 \% \pm 221$ & 8.2 & 7.6 \\
\hline $\begin{array}{c}\text { Adults } \\
\mathrm{n}=278\end{array}$ & $\pm 9.7 \%$ & $\pm 251 \%$ & $10.4 \% \pm 8.9$ & $-212 \% \pm 214$ & 7.9 & 6.9 \\
\hline $\begin{array}{c}\text { Children } \\
\mathrm{n}=95\end{array}$ & $\pm 13.4 \%$ & $\pm 279 \%$ & $12.6 \% \pm 10.5$ & $-249 \% \pm 239$ & 9.3 & 9.5 \\
\hline $\begin{array}{c}2 \text { tests } \geq \\
10 \% \\
n=72\end{array}$ & $\pm 14.6 \%$ & $\pm 373 \%$ & $24.7 \% \pm 9.7$ & $-525 \% \pm 245$ & 20.8 & 10.3 \\
\hline $\begin{array}{c}2 \text { tests } \geq \\
15 \% \\
n=34\end{array}$ & $\pm 12.2 \%$ & $\pm 411 \%$ & $29.4 \pm 8.5$ & $-613 \% \pm 259$ & 25.9 & 8.6 \\
\hline $\begin{array}{c}2 \text { tests } \geq \\
20 \% \\
\mathrm{n}=19\end{array}$ & \pm 14.3 & $\pm 470 \%$ & $34.0 \pm 8.2$ & $-707 \% \pm 246$ & 30.1 & 10.1 \\
\hline $\begin{array}{c}1 \text { test } \geq 10 \% \\
\mathrm{n}=89\end{array}$ & \pm 15.7 & $\pm 370 \%$ & $14.3 \pm 4.8$ & $-289 \% \pm 151$ & 9.4 & 11.1 \\
\hline $\begin{array}{c}2 \text { tests }<10 \% \\
n=212\end{array}$ & $\pm 5.2 \%$ & $\pm 117 \%$ & $4.9 \% \pm 2.9$ & $-89 \% \pm 75$ & 3.5 & 3.7 \\
\hline $\begin{array}{c}2 \text { tests }< \\
15 \% \\
n=288\end{array}$ & $\pm 7.1 \%$ & $\pm 168 \%$ & $6.8 \% \pm 4.2$ & $-132 \% \pm 107$ & 4.9 & 5.0 \\
\hline \multicolumn{7}{|l|}{$\begin{array}{l}\text { NAEPP } \\
\text { Scores }\end{array}$} \\
\hline $\begin{array}{l}\text { NAEPP }=1 \\
\mathrm{n}=309\end{array}$ & $\pm 10.7 \%$ & $\pm 252 \%$ & $10.7 \% \pm 9.2$ & $-206 \% \pm 211$ & 8.1 & 7.5 \\
\hline $\begin{array}{l}\text { NAEPP }>1 \\
\mathrm{n}=64\end{array}$ & $\pm 11.4 \%$ & $\pm 289 \%$ & $12.0 \% \pm 10.1$ & $-249 \% \pm 248$ & 9.1 & 8.1 \\
\hline $\begin{array}{l}\text { NAEPP }=2 \\
n=48\end{array}$ & $\pm 10.3 \%$ & $\pm 284 \%$ & $10.3 \% \pm 8.9$ & $-228 \% \pm 252$ & 7.8 & 7.3 \\
\hline $\begin{array}{l}\text { NAEPP }=3 \\
n=16\end{array}$ & $\pm 14.6 \%$ & $\pm 312 \%$ & $17.1 \pm 11.8$ & $-313 \% \pm 235$ & 12.9 & 10.3 \\
\hline
\end{tabular}

There was no significant difference in the HR, \% of predicted maximum at 2 and 6 minutes on the day of the highest percent fall in $\mathrm{FEV}_{1}$ of $82.0 \% \pm 5.0$ and $87.4 \% \pm 5.0$ in adults, and $82.4 \% \pm 5.1$ and $86.9 \% \pm 5.1$ in children.

The distribution of the estimated ventilation as \% of MVV during the exercise is shown in Figure 7. The mean estimated ventilation calculated as a percent of maximum voluntary ventilation during the $2^{\text {nd }}$ and $6^{\text {th }}$ minute of the exercise with the highest fall in $\mathrm{FEV}_{1}$ was $57.3 \% \pm 14.5$ and $53.1 \% \pm 12.9$ for adults and $54.6 \% \pm$ 12.9 and $51.1 \% \pm 11.0$ for the children. The estimated ventilation as $\%$ of MVV on the $2^{\text {nd }}$ exercise test showed a small $(+1.21 \% \mathrm{MVV})$ though significantly $(<0.009)$ higher value compared with the $1^{\text {st }}$ test for adults and a small $(+1.35 \%$ MVV) but not significantly $(\mathrm{P}<0.052)$ different value for children.
There was no significant difference between the HR \% predicted and estimated ventilation \% MVV between the test on the day the highest \% fall in $\mathrm{FEV}_{1}$ was documented, and on the test on the day the lowest \% fall in $\mathrm{FEV}_{1}$ was recorded for the different groups of subjects (data not shown). There was also no significant difference in baseline $\mathrm{FEV}_{1} \%$ predicted for the two days in the group where the $\%$ falls in $\mathrm{FEV}_{1} \geq 10 \%$ with both tests. The $\mathrm{FEV}_{1} \%$ predicted was higher on the day of the highest $\%$ fall in $\mathrm{FEV}_{1}$ for all the other groups; however, the baseline values for $\mathrm{FEV}_{1} \%$ predicted were always above $90 \%$ and all the differences were less than $2.4 \%$ predicted.

\section{Discussion}

One problem in using an exercise challenge to identify EIB in the laboratory is ensuring that intensity of 

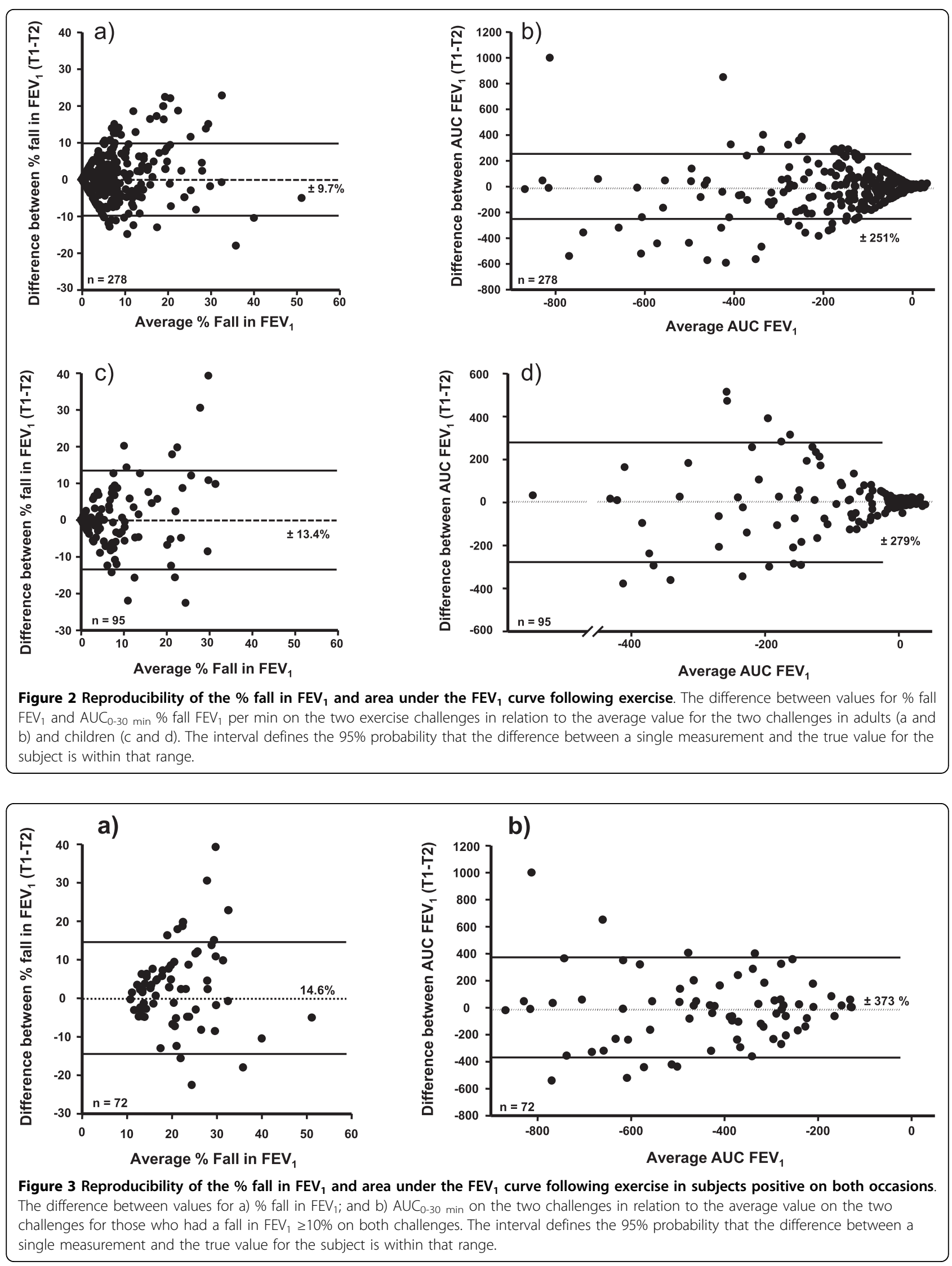


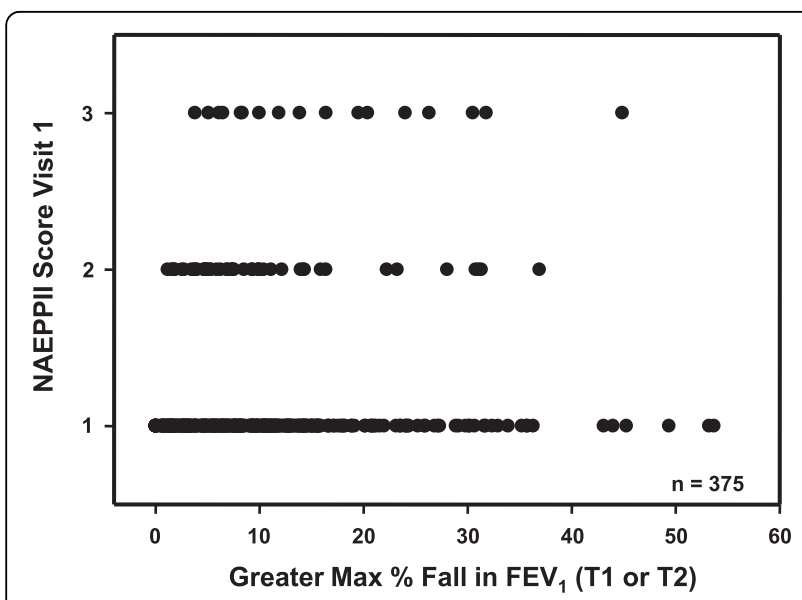

Figure $4 \%$ fall in $\mathrm{FEV}_{1}$ in relation to NAEPPII severity score. Individual values for the maximum \% fall in $\mathrm{FEV}_{1}$ after exercise in relation to the NAEPPII severity grading for asthma.

exercise, exercise duration, and condition of the inspired air are controlled and are adequate for eliciting the EIB response. In this multicentre study exercise duration was 8 minutes, inspired air was dry, and intensity of exercise was sufficient for HR to reach the value required by the protocol, i.e. $80-90 \%$ predicted maximum by the $2^{\text {nd }}$ minute of exercise and HR was not significantly different on the two test days. Appropriate times for withdrawal of medications were verified and pre-exercise $\mathrm{FEV}_{1}$ was $>70 \%$ predicted in all but 2 subjects (both children) and it was similar on both occasions (and was actually greater than a mean of $90 \%$ ). No subject had taken inhaled corticosteroids within the last 4 weeks, or long or short- acting beta ${ }_{2}$ agonist for
48 hours or 8 hours, respectively. Minimising the difference in these variables between tests allowed us to examine the natural variation of the airway response within a few days. We used one time point $\geq 10 \%$ fall to identify a positive test because this has been common practice. However we allowed a period of 5 minutes for recovery before the first $\mathrm{FEV}_{1}$ was measured. We excluded those who were symptomatic to the allergens to which they tested positive to a skin test at the time to reduce variability due to environmental factors. We are unaware of any other study that has given this level of attention to variables when performing two exercise challenges to identify EIB. Knowledge about normal variation in the exercise response is critically important when interpreting a negative test or when evaluating an exercise response to a therapeutic agent.

The ventilation reached and sustained during exercise is a primary determinant of the $\%$ fall in $\mathrm{FEV}_{1}$ [4]. However equipment for measuring ventilation during exercise is expensive and heart rate has been preferred to confirm the intensity of exercise in the United States of America. To ensure that subjects reached the minimum ventilation (40\% of MVV recommended by other protocols [4]) we made an estimate of oxygen consumption from the speed and slope of the treadmill and the weight of the subject protocols and assumed a ventilatory equivalent of $27 \mathrm{~L}$ of ventilation per $\mathrm{L}$ of $\mathrm{VO}_{2}$ using published equations [4]. This target ventilation was achieved between by the $2^{\text {nd }}$ minute of exercise and MVV exceeded $50 \%$ in the majority of adults and children. While a direct measurement of ventilation would have been preferable the estimated values, based on the work load and expressed as a $\% \mathrm{MVV}$, at $2 \mathrm{~min}$ and

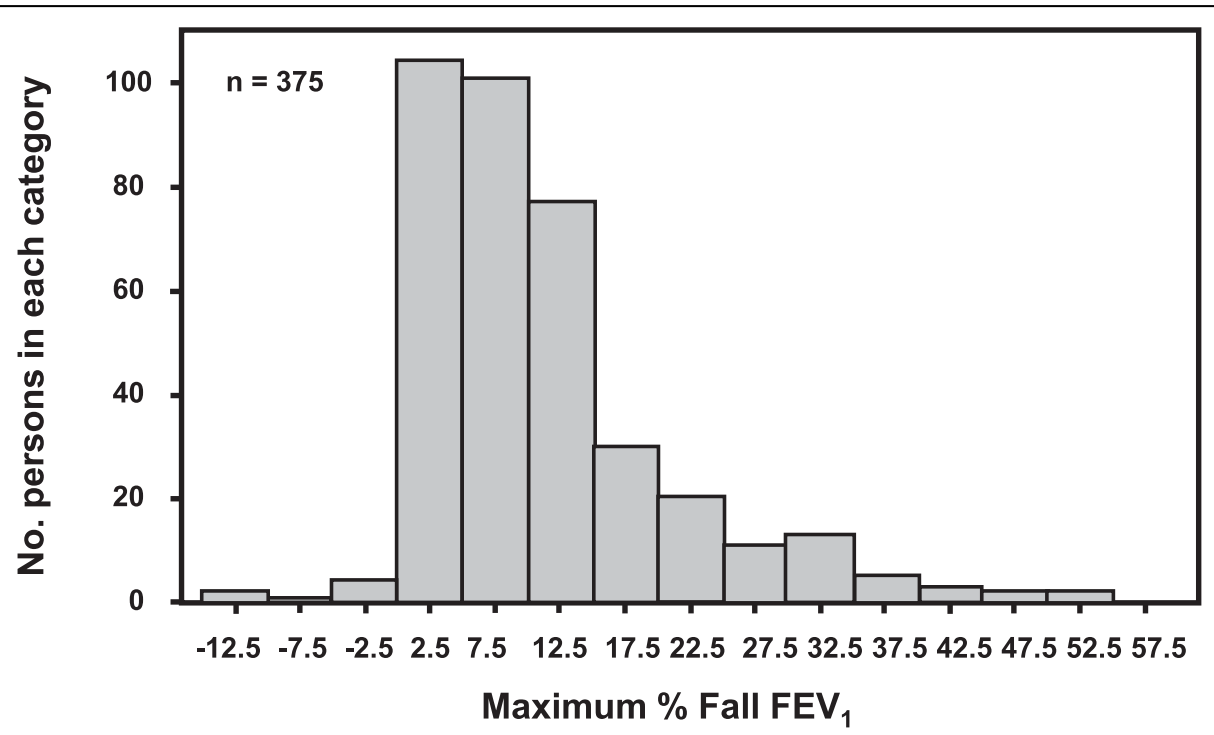

Figure 5 Distribution of the maximum \% fall in $\mathrm{FEV}_{\mathbf{1}}$. Distribution of the highest \% fall in $\mathrm{FEV}_{\mathbf{1}}$ after exercise challenge in 375 subjects. 


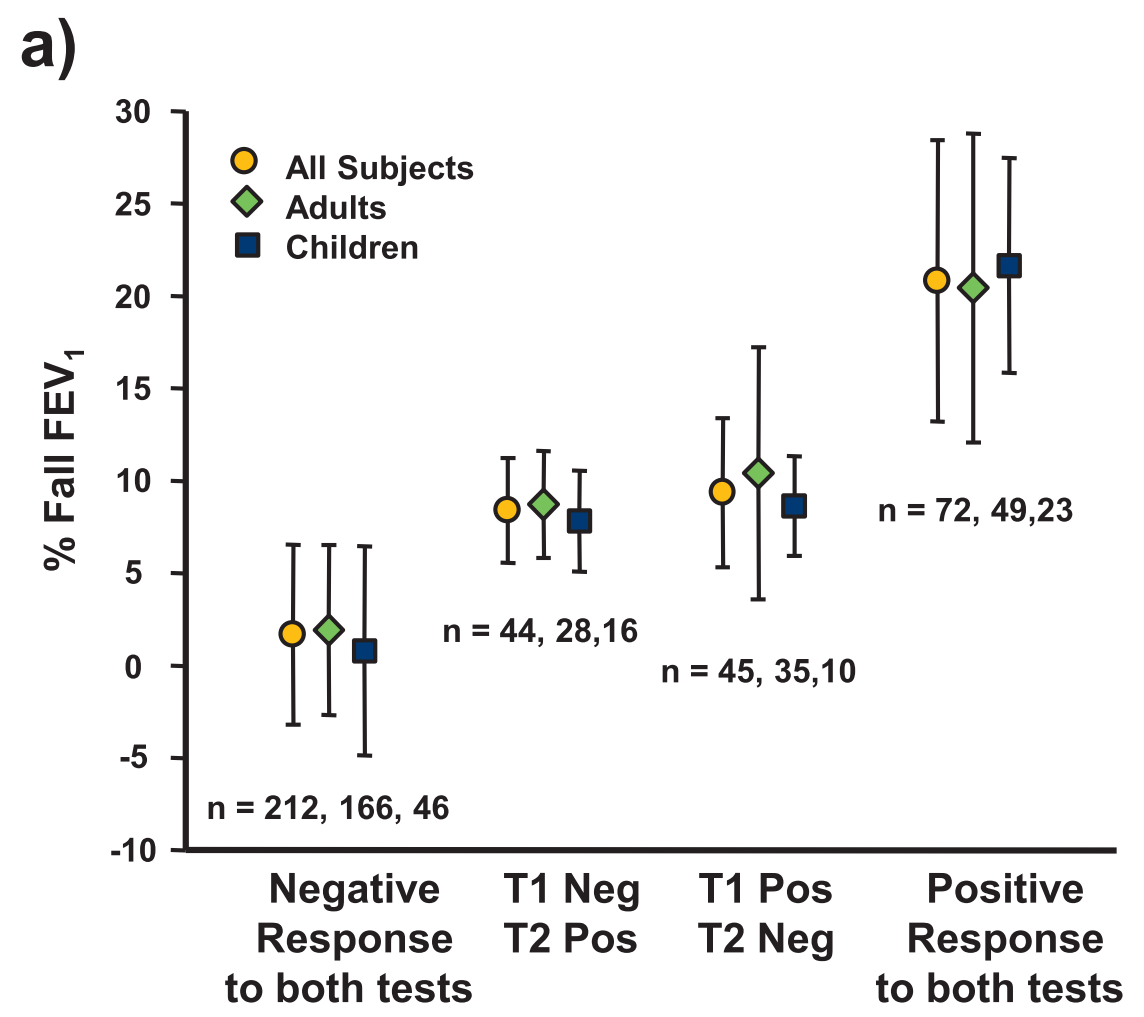

b)

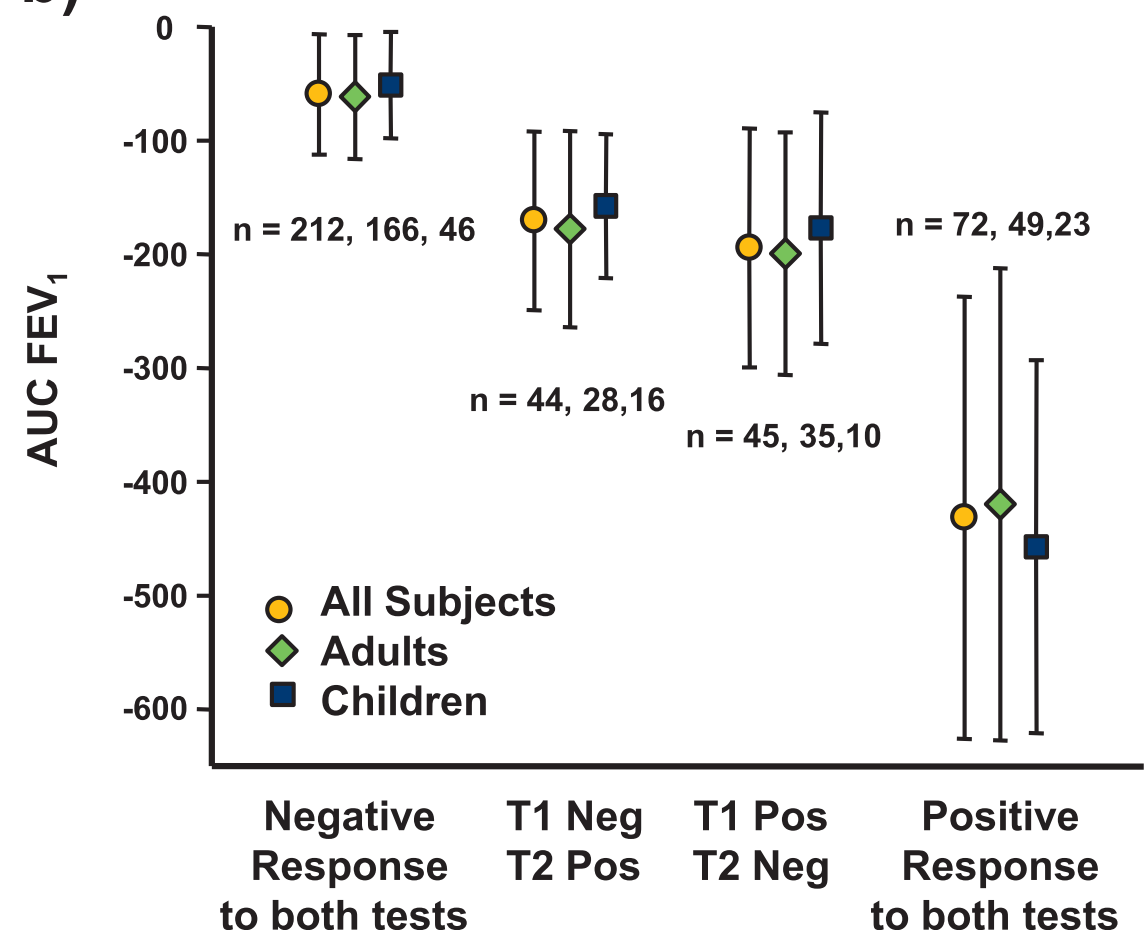

Figure $\mathbf{6} \%$ fall in $\mathrm{FEV}_{\mathbf{1}}$ and AUC on the two exercise tests. The mean and standard deviation for:- a) average \% fall FEV $\mathrm{V}_{1}$ on exercise; b)

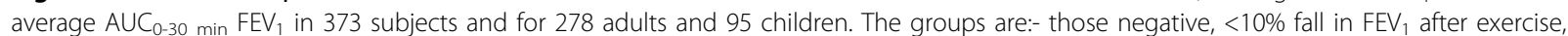
those negative/positive and positive/negative on the $1^{\text {st }}$ and $2^{\text {nd }}$ challenge, and those with two positive challenges, i.e. $\geq 10 \%$ fall in FEV 1 . 


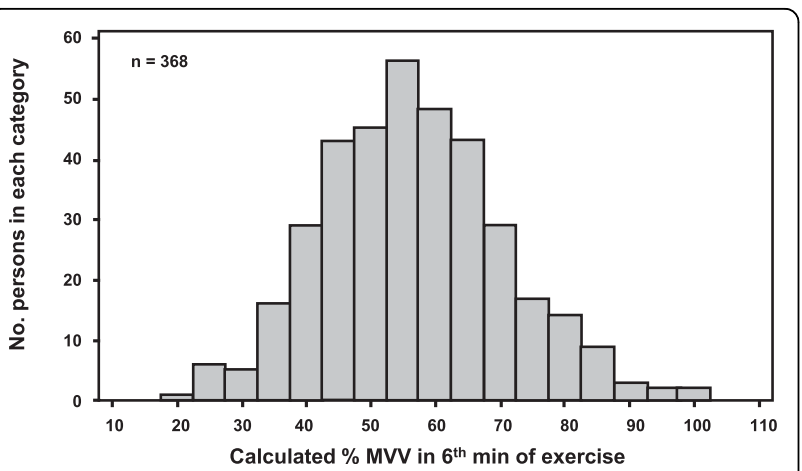

Figure 7 Distribution of the \% of maximum voluntary ventilation during the $6^{\text {th }}$ minute of exercise. Distribution of the values estimated for percentage of maximum voluntary ventilation during exercise test on the test when the highest fall in $\mathrm{FEV}_{\mathbf{1}}$ was measured.

6 min were the same as the values measured in adults during 8 minutes of bicycle exercise [25].

As may have been expected from a group of patients without a definitive diagnosis of asthma, the response to exercise, when positive, was mild and $77 \%$ of the subjects had a fall in $\mathrm{FEV}_{1}<15 \%$ on both exercise challenges. In only 34 of 161 subjects did a $\geq 15 \%$ fall occur on both exercise challenges, a frequency probably consistent with their mild symptoms and indefinite diagnosis of asthma. A fall in $\mathrm{FEV}_{1}$ after exercise of $\geq 20 \%$ is the value suggested for inclusion in clinical trials to evaluate a drug for EIB (FDA Guidance for Industry, http://www.fda.gov./cder/guidance). This value occurred on two exercise challenges in only 19 of the 161 subjects (11.8\%) with EIB in this study or only in $5.1 \%$ of the subjects who were exercised twice.

For those who had two exercise challenges with falls greater than $10 \%$, the mean maximum fall after exercise was $24.7 \% \pm 9.7$, leaving little doubt about a diagnosis of EIB. The reproducibility of the response in this group was $\pm 14.6 \%$ and compares well with the value of $\pm 15.8 \%$ calculated in adults with an established diagnosis of asthma performing repeated exercise on a cycle ergometer [25].

We assigned a value of $0 \%$ fall for those demonstrating only a rise in $\mathrm{FEV}_{1}$ in response to exercise; a post-exercise fall is characteristic of asthma while a post-exercise rise in $\mathrm{FEV}_{1}$ is not and occurs in many non-asthmatic subjects [26]. The mean maximum fall in $\mathrm{FEV}_{1}$ plus 2SDs $(4.9 \% \pm$ SD 2.9) for the group with two negative challenges (e.g. those who had $<10 \%$ fall in $\mathrm{FEV}_{1}$ on both challenges) was $10.7 \%$ and similar to that reported for groups of normal adults or children, without a history of symptoms of asthma, exercising in ambient air in a laboratory $[2,10,27]$. Thus, subjects with an NAEPPII asthma severity score of $\geq 1$ can have a reproducible response to exercise similar to that of a healthy subject with no history of asthma

The study results confirm that there is little difference between adults and children for the indices used to express EIB and we used a value of $10 \%$ in both groups. However higher cut-off values have been recommended to identify EIB in children [28,29]. Using the $15 \%$ cut point recommended by Haby [28], the prevalence of EIB in the children was reduced from $51.5 \%(49 / 95)$ to $28.4 \%(27 / 95)$. We consider that the 5 times difference in the degree of EIB in those with $\geq 10 \%$ fall in FEV 1 $(24.7 \% \pm 9.7)$ on both occasions and those with $\leq 10 \%$ fall on both occasions $(4.9 \% \pm 2.9)$ supports the use of a $10 \%$ cut-off to include or exclude a definitive diagnosis of EIB when challenges are repeated over a short period.

We used a cut off point of $\geq 10 \%$ fall in $\mathrm{FEV}_{1}$ to analyse the $\mathrm{AUC}_{0-30 \mathrm{~min}}$ and its reproducibility. There was also $>5$ times difference in the $\mathrm{AUC}_{0-30}$ min between those with two challenges with $\geq 10 \%$ fall in $\mathrm{FEV}_{1}(-525 \pm 245 \%$ $\mathrm{FEV}_{1} \mathrm{~min}^{-1}$ ) compared with those with two challenges with $<10 \%$ fall in $\mathrm{FEV}_{1}\left(-89 \pm 75 \% \mathrm{FEV}_{1} \mathrm{~min}^{-1}\right)$. Based on the mean plus 2SDs in those with two challenges with $<10 \%$ fall in $\mathrm{FEV}_{1}$, we suggest an upper cut-off value for $\mathrm{AUC}_{0-30}$ min of $240 \%$ fall in $\mathrm{FEV}_{1} \mathrm{~min}^{-1}$ for a negative test. The utility of having values for the reproducibility of $\mathrm{AUC}_{0-30 \text { min }}$ is that there are drugs such as montelukast that have limited effect on the maximum \% fall in $\mathrm{FEV}_{1}$ but have a profound benefit in enhancing recovery of $\mathrm{FEV}_{1}$ to baseline [5]. In keeping with others [30] who reported a smaller group of known asthmatic subjects over a longer period, the values for reproducibility of the $\%$ fall in $\mathrm{FEV}_{1}$ were superior to the $\mathrm{AUC}_{0-30}$ min.

In the 89 subjects positive on only one challenge (Figure 6) we considered that this variation may have been due to a change in the intensity of exercise on the two test days or perhaps other characteristics of this group. However the variation in the \% fall in $\mathrm{FEV}_{1}$ on the two test days was not explained by differences in the ventilation \% MVV, HR \% predicted maximum. The $\mathrm{FEV}_{1} \%$ predicted was significantly higher $(\mathrm{p}<0.02)$ on the day of the positive challenge $(92.1 \% \pm 11.3)$ compared with the day of the negative test $(90.2 \% \pm 11.1)$ although the difference was small. The variability between a positive and negative test result may be due to other factors, perhaps environmental or dietary, or simply the intrinsic reproducibility of the test itself.

The study group had mild symptoms and signs suggestive of asthma but the NAEPPII grading could not be relied upon either to identify EIB or to predict its severity or reproducibility of the response. However, the NAEPPII is a score of asthma severity [14] and does not necessarily include symptoms provoked by exercise. This may not be important in that other investigators who have questioned subjects specifically about exercise 
symptoms have found symptoms alone to be unreliable predictors of either presence or severity of EIB $[10,31,32]$.

The data presented here are a secondary analysis of a previously reported study (NCT00252291) [13]. The protocol required two exercise challenge tests to be performed under the same controlled conditions on consecutive visits prior to a mannitol and a methacholine challenge. All but two subjects of the 375 in the previously reported study performed two challenge tests. For these reasons this study offered an ideal opportunity to determine reproducibility of the response to exercise in a large group in an unbiased manner.

The usefulness of these data are not only in understanding that more than one test may be required to exclude a diagnosis of EIB but also in determining the benefit of treatment or how severe EIB should be for inclusion in a drug trial. For example the variability in the $\%$ fall in $\mathrm{FEV}_{1}$ as expressed by the $95 \%$ probability value for subjects with two tests $\geq 20 \%$ was $14.3 \%$ and the mean \% fall in $\mathrm{FEV}_{1}$ was $30.3 \%$. That means that on a second test a subject with a fall of $30.1 \%$ on initial testing would fall $30.1 \% \pm 14.3 \%$ (range $44.4-15.8 \%$ ) on a second occasion exercising under identical conditions within a few days. Thus for a drug to be regarded as beneficial the \% fall would need to be less than $15.8 \%$ on repeated challenge.

In our subjects with mild symptoms of asthma, good lung function, and a low response rate to bronchodilator, a single exercise test did not rule out mild EIB and a second exercise test under the same conditions identified an extra 44 subjects, $27 \%$ of the total positive, with $\geq 10 \%$ fall in $\mathrm{FEV}_{1}$. It is unlikely that repeat exercise challenge is useful in those recording a rise in $\mathrm{FEV}_{1}$ on the initial challenge, as the chance of being positive on the second test was low and, even when the exercise challenge was positive, the falls in $\mathrm{FEV}_{1}$ were very mild.

\section{Conclusions}

The majority of subjects with signs and symptoms suggestive of asthma without a definitive diagnosis will have the same outcome i.e. positive or negative test result following rechallenge when exercise is standardized for intensity, duration, and condition of the inspired air. However a minority will have a positive test result on only one exercise test. These data also show that for most subjects the EIB will be mild $\left(<15 \%\right.$ fall in $\left.\mathrm{FEV}_{1}\right)$ and particularly so for those positive on a second challenge after the first exercise challenge was negative. This study provides evidence for the degree of variability in response to duplicate exercise challenges and suggests that for some subjects with mild symptoms more than one test may be required before either a diagnosis of
EIB is excluded or prophylactic treatment is prescribed. Finally, these data in a large number of adults indicate that the reproducibility of the response in adults is similar to that observed in children.

\section{Abbreviations}

$\mathrm{AUC}_{0-30}$ min: area under the \% fall in $\mathrm{FEV}_{1}$ time curve; $\mathrm{BHR}$ : bronchial hyperresponsiveness; CDL: ClinDataLink; ElB: exercise-induced

bronchoconstriction; $\mathrm{FEV}_{1}$ : forced expiratory volume in one second; FVC: forced vital capacity; ITT: intention to treat; MW: \% of maximum voluntary ventilation; NAEPPII: National Asthma Education and Prevention Program II: $\mathrm{NIH}$ National Institutes of Health; PPP: per protocol population.

\section{Acknowledgements}

\section{The A305 Study Group - Principal Investigators:}

Homer Boushey, University of California, CA; Thomas Casale, Creighton University Allergy Division, Creighton University Medical Center, NE; Linda Ford, The Asthma and Allergy Center, P.C., NE; Leon Greos, Colorado Allergy \& Asthma Centers, PC, CO; Phillip Halverson, Clinical Research Institute, MN; Frank Hampel, Central Texas Health Research, TX; Phillip Korenblat, The Clinical Research Center, MO; Craig LaForce, North Carolina Clinical Research, NC; Anne-Marie Irani, Children's Medical Center, VA; Jonathon Matz, Chesapeake Medical Center, MD; Anjuli Nayak, Sneeze, Wheeze \& Itch Associates, LLC, IL; Nancy Ostrum, Allergy \& Asthma Medical Group and Research Center, CA; David Pearlman, Colorado Allergy and Asthma Centers, PC, CO; Andrew Pedinoff, Princeton Center for Clinical Research, NJ; Bruce Prenner, Allergy Associates Medical Group, Inc., CA; Paul Qaqundah, Pediatric Care Medical Group, Inc. CA; Javier Quesada, West Coast Clinical Trials, CA; Paul Ratner, Sylvana Research Associates, PA, TX; Kenneth Rundell, Keith J. O'Neil Center for Healthy Families, Marywood University, PA; Gail Shapiro, A. S.T.H.M.A., Inc., WA; Christine Sorkness, Allergy and Asthma Clinical Research, Wl; Sheldon Spector, California Allergy and Asthma Medical Group, CA; Ricardo Tan, California Allergy and Asthma, Palmdale, CA; Steven Weinstein, Allergy and Asthma Specialists, Medical Group and Research Center, CA; Robert Ziering, Allergy and Immunology Medical Group, CA;

This study was a Phase III clinical trial study funded by Pharmaxis Ltd, NSW Australia 2086. Dr. Brett Charlton of Pharmaxis Ltd was involved in designing the study and identifying the statistics used in the analysis.

\section{Author details}

${ }^{1}$ Department of Respiratory \& Sleep Medicine, 11 West, Royal Prince Alfred Hospital, Missenden Road, Camperdown NSW 2050, Australia. ${ }^{2}$ Sydney Medical School, University of Sydney, NSW 2006, Australia. ${ }^{3}$ Colorado Allergy and Asthma Centers, Suite 150/125 Rampart Way, Denver CO 80230- 6405, USA. ${ }^{4}$ Professor of The Basic Sciences, The Commonwealth Medical College, 150 North Washington Avenue, Scranton PA, PA 18503-1843, USA.

${ }^{5}$ Department of Respiratory \& Sleep Medicine, 11 West, Royal Prince Alfred Hospital, Missenden Road, Camperdown NSW 2050, Australia. ${ }^{6}$ Asthma Clinical Research Center, University of California, San Francisco CA 90089, USA. ${ }^{7}$ Department of Medicine, Allergy and Asthma Clinical Research, University of Wisconsin, Madison, WI 53705, USA. ${ }^{8}$ CompleWare Corporation, PO Box 3090, North Liberty, IA 52317, USA. ${ }^{9}$ Department of Internal Medicine, University of lowa, lowa City, IA52242, USA.

\section{Authors' contributions}

SDA \& JMW designed the protocol, DSP, KWR, HB, \& CAS were investigators and exercised the subjects, CP \& SN carried out the statistical analysis, SDA drafted the manuscript but all of the authors contributed to the manuscript. All authors read and approved the final manuscript.

\section{Authors' Information}

SDA, DSP, KWR, HB \& JMW have all published in the field of exerciseinduced bronchoconstriction, both in adults and children, over a long period of time. They appreciated the opportunity afforded by design of the protocol standardized for the intensity and duration of exercise, and the condition of inspired air. This allowed, for the first time, a detailed analysis of reproducibility in subjects most likely to be referred to a laboratory for exercise testing to identify EIB, i.e. subjects with mild symptoms of asthma but without a definite diagnosis. 
Homer Boushey is Chief of the Division of Allergy/Immunology and Director of the Asthma Clinical Research Center at the University of California.

\section{Competing interests}

SDA is the inventor of the mannitol test however the intellectual property is owned by her employer, the Sydney South West Area Health Service (SSWAHS). SDA receives a 10\% share of the royalties paid to SSWAHS. SDA has undertaken research studies that were funded by Pharmaxis. She is a shareholder in Pharmaxis but holds no options. She acts as a consultant to Pharmaxis for which she has received fees since April 2009.

DSP, KWR, HB, CAS participated in the study through their respective centers (see below) that received a research grant for study participation from Pharmaxis Ltd.

CPP owns shares in Pharmaxis Ltd which she herself has purchased. She has also acted as a paid consultant to Pharmaxis

$\mathrm{SN}$ is the statistician employed by CompleWare and carried out the statistical analysis.

JW is the President of, and is a shareholder in, CompleWare Corporation.

CompleWare received a fee from Pharmaxis $L t d$. for services in carrying out the clinical trial.

There are no other competing interests or conflicts of interest.

Received: 9 April 2010 Accepted: 1 September 2010

Published: 1 September 2010

\section{References}

1. Anderson SD: Exercise-induced asthma. In Allergy \& Allergic Diseases. Edited by: Kay AB. Oxford: Blackwell Scientific Publications; 1997:

2. Kattan $M$, Thomas $C M$, Keens TG, Mellis CM, Levison $H$ : The response to exercise in normal and asthmatic children. J Pediatr 1978, 92(5):718-721.

3. Sterk PJ, Fabbri LM, Quanjer PH, Cockcroft DW, O'Byrne PM, Anderson SD, Juniper EF, Malo J-L: Airway responsiveness: Standardized challenge testing with pharmacological, physical and sensitizing stimuli in adults. Eur Respir J 1993, 6(Suppl 16):53-83.

4. Crapo RO, Casaburi $\mathrm{R}$, Coates $\mathrm{AL}$, Enright $\mathrm{PL}$, Hankinson JL, Irvin CG, MacIntyre NR, McKay RT, Wanger JS, Anderson SD, Cockcroft DW, Fish JE, Sterk PJ: Guidelines for methacholine and exercise challenge testing 1999. Am J Respir Crit Care Med 2000, 161(1):309-329.

5. Kemp JP, Dockhorn RJ, Shapiro GG, Nguyen HH, Reiss TF, Seidenberg BC, Knorr B: Montelukast once daily inhibits exercise-induced bronchoconstriction in 6- to 14-year-old children with asthma. J Pediatr 1998, 133(3):424-428

6. Finnerty JP, Holgate ST: Evidence for the roles of histamine and prostaglandins as mediators in exercise-induced asthma: the inhibitory effect of terfenadine and flurbiprofen alone and in combination. Eur Respir J 1990, 3:540-547.

7. Dahlén B, Roquet A, Inman MD, Karlsson Ö, Naya I, Anstrén G, O’Byrne PM Dahlén S-E: Influence of zafirlukast and loratadine on exercise-induced bronchoconstriction. J Allergy Clin Immunol 2002, 109(5 Pt 1):789-793.

8. Cabral ALB, Conceição GM, Fonseca-Guedes CHF, Martins MA: Exerciseinduced bronchospasm in children. Am J Respir Crit Care Med 1999, 159:1819-1823.

9. Haby MM, Anderson SD, Peat JK, Mellis CM, Toelle BG, Woolcock AJ: An exercise challenge protocol for epidemiological studies of asthma in children: comparison with histamine challenge. Eur Respir J 1994, 7:43-49.

10. Rundell KW, Im J, Mayers LB, Wilber RL, Szmedra L, Schmitz HR: Selfreported symptoms and exercise-induced asthma in the elite athlete. Med Sci Sports Exerc 2001, 33(2):208-213.

11. Sinclair DG, Sims MM, Hoad NA, Winfield CR: Exercise-induced airway narrowing in army recruits with a history of childhood asthma. Eur Respir J 1995, 8(8):1314-1317.

12. Ernst $P$, Ghezzo $H$, Becklake MR: Risk factors for bronchial hyperresponsiveness in late childhood and early adolescence. Eur Respir J 2002, 20(3):635-639.

13. Anderson SD, Charlton B, Weiler JM, Nichols S, Spector SL, Pearlman DS, A305 Study Group: Comparison of mannitol and methacholine to predict exercise-induced bronchoconstriction and a clinical diagnosis of asthma. Respir Res 2009, 10:4.

14. National Heart Lung and Blood Institute: Expert Panel Report 2: Guidelines for the Diagnosis and Management of Asthma NIH. Bethesda (MD): NIH Publications, 11997.
15. Polgar G, Promadhat V: Pulmonary Function Testing in Children: Techniques and Standards. Philadelphia: W.B. Saunders Co 1971.

16. Crapo RO, Morris AH, Gardner RM: Reference spirometric values using techniques and equipment that meet ATS recommendations. Am Rev Respir Dis 1981, 123(6):659-664

17. Weiler JM, Nathan RA, Rupp NT, Kalberg CJ, Emmett A, Dorinsky PM: Effect of fluticasone/salmeterol administered via a single device on exerciseinduced bronchospasm in patients with persistent asthma. Ann Allergy Asthma Immunol 2005, 94:65-72.

18. Gandevia B, Hugh Jones P: Terminology for measurements of ventilatory capacity. Thorax 1957, 12:290-293.

19. Atkinson KA: An Introduction to Numerical Analysis. New York: John Wiley \& Sons, 21989.

20. Miller MR, Hankinson JL, Brusasco V, Burgos F, Casaburi R, Coates A, Crapo R, Enright P, van der Grinten CPM, Gustafsson P, Jensen $R_{\text {, }}$ Johnson DC, Maclntyre N, McKay R, Navajas D, Pedersen OF, Pellegrino R, Viegi G, Wanger J: Standardisation of spirometry. Eur Respir J 2005 26(2):319-338

21. Franklin BA, Balady G: ACSM's guidelines for exercise testing and prescription. University of Michigan: Lippincott Williams \& Wilkins, 62000.

22. Jones NL: Clinical Exercise Testing. Philadelphia: WB Saunders, 41997.

23. Bland JM, Altman DG: Statistical methods for assessing agreement between two methods of clinical measurement. Lancet 1986, 1:307-310.

24. Chinn S: Repeatability and method comparison. Thorax 1991, 46:454-456.

25. Anderson SD, Lambert S, Brannan JD, Wood RJ, Koskela H, Morton AR, Fitch KD: Laboratory protocol for exercise asthma to evaluate salbutamol given by two devices. Med Sci Sports Exerc 2001, 33(6):893-900.

26. Godfrey S: Exercise testing in children. London: W.B. Saunders 1974.

27. Helenius IJ, Tikkanen HO, Haahtela T: Occurrence of exercise induced bronchospasm in elite runners: dependence on atopy and exposure to cold air and pollen. Br J Sports Med 1998, 32:125-129.

28. Haby MM, Peat JK, Mellis CM, Anderson SD, Woolcock AJ: An exercise challenge for epidemiological studies of childhood asthma: validity and repeatability. Eur Respir J 1995, 8(5):729-736.

29. Godfrey S, Springer C, Bar-Yishay E, Avital A: Cut-off points defining normal and asthmatic bronchial reactivity to exercise and inhalation challenges in children and young adults. Eur Respir J 1999, 14(3):659-668.

30. Dahlén B, O'Byrne PM, Watson RM, Roquet A, Larsen F, Inman MD: The reproducibility and sample size requirements of exercise-induced bronchoconstriction measurements. Eur Respir J 2001, 17(4):581-588.

31. Rupp NT, Brudno S, Guill MF: The value of screening for risk of exerciseinduced asthma in high school athletes. Ann Allergy 1993, 70:339-342.

32. Holzer $\mathrm{K}$, Anderson SD, Douglass J: Exercise in elite summer athletes: Challenges for diagnosis. J Allergy Clin Immunol 2002, 110(3):374-380.

doi:10.1186/1465-9921-11-120

Cite this article as: Anderson et al:: Reproducibility of the airway response to an exercise protocol standardized for intensity, duration, and inspired air conditions, in subjects with symptoms suggestive of asthma. Respiratory Research 2010 11:120.

\section{Submit your next manuscript to BioMed Central and take full advantage of:}

- Convenient online submission

- Thorough peer review

- No space constraints or color figure charges

- Immediate publication on acceptance

- Inclusion in PubMed, CAS, Scopus and Google Scholar

- Research which is freely available for redistribution

Submit your manuscript at www.biomedcentral com/submit
C Biomed Central 